\title{
PENGELOLAAN UNICORN PADA BUKALAPAK
}

\author{
Andry Andaru \\ 155100006 \\ Fakultas Komputer \\ andryandaru.student@umitra.ac.id
}

\begin{abstract}
kemajuan teknologi telah mempengaruhi caramanusia melakukan proses transaksi(Ustadianto,Ariani:2007).Komunikasi danpertukaran informasi pada kegiatan bisnis menjadi semakin mudah dengan adanyainternet sehingga perusahaan dapat melakukan aktivitas bisnisnya secaraelektronik khususnya aktivitas hubungan perusahaan dengan konsumen dan mitrakerja perusahaan atau disebute-commerce.Ecommerceadalah penggunaaninternetdan web untuk transaksi bisnis dan danecommercesecara digital mampumempermudah transaksi komersial antar organisasi dan antara organisasi denganindividu(Laudon,2010:8).Menteri Komunikasi dan Informatika, Rudiantaramenyatakan bahwapotensi perdagangane-commercepada tahun 2015diperkirakan mencapai US\$ 20 miliar atau sekitar Rp 280 triliun. Nilainya lebihbesar dari pencapaian tahun 2014 sebesar US\$ 12 miliar dan senilai US\$ 8 milliar

3pada 2013. Saban tahun, pertumbuhannya sekitar 60 persen hingga 70 persen(Katadata.co.id, 2015).Menurut data hasil riset Asosiasi Penyelenggara Jasa Internet Indonesia(APJII) tahun 2014 mengungkapkan pengguna internet di Indonesia terhitungsejak tahun 2005 hingga tahun 2014 tumbuh sebesar 72,1 juta dengan penetrasi27,1 persen. Sedangkan jumlah pengguna internet di Indonesia tahun 2014 mencapai 88,1 juta orang hingga akhir tahun, tumbuh 16,2 juta dari tahunsebelumnya 71,9 juta dan memiliki penetrasi 34,9 persen(APJII, 2014).
\end{abstract}

Kata Kunci : pengelolaan unicorn pada bukalapak 


\section{A. PENDAHULUAN}

Bukalapak merupakan salah satuonline marketplacedi Indonesiayangmenyediakan sarana jual-beli dari konsumen ke konsumen. Siapa pun dapatmembuka tokoonlinedi Bukalapak dan melayani pembeli dari seluruh Indonesiauntuk transaksi satuan maupun banyak. Bukalapak memiliki slogan jual-belionlinemudah dan terpercaya karena Bukalapak memberikan jaminan 100 persenuang kembali kepada pembeli jika barang tidak dikirimkan oleh pelapak

Bukalapak didirikan Achmad Zaky pada tahun 2010 sebagai bentukportofolio dari Suitmedia, sebuah konsultan danlab digital. Namun, Bukalapakbaru berstatus sebagai sebuah Perseroan Terbatas (PT) pada September 2011 dandikelola oleh manajemen yang dipimpin oleh Achmad Zaky sebagai CEO (ChiefExecutive Office)dan Nugroho Herucahyono sebagai CTO (Chief TechnologyOfficer)

(Mysharing.co, 2015). Kantor Bukalapak beralamat di Plaza City ViewLt.1 Jl. Kemang Timur No.22 Pasar Minggu, Pejaten Barat Jakarta, Indonesia12510.Setelah berdiri selama setahun, Bukalapak mendapat tambahan investasidana dari Batavia Incubator,sebuah perusahaan inkubasi teknologi asal
Jepang.Didirikan sebagaijoint ventureantara Rebright Partners, inkubator asal Jepang 2dan Corfina Group, grup finansial Indonesia.Kemudian setahun berikutnyaBukalapak menerima pendanaan dari perusahaan investasi Jepang GREEVentures.

(Dailysocial.id, 2012).Seiring dengan berjalannya waktu, Bukalapak semakin berkembangdengan inovasi terbarunya untuk mempermudah para pengguna Bukalapak

untuktransaksinya.Bukalapak

memiliki program untuk memfasilitasi

parapelakuUKMyang ada di Indonesia untuk melakukan transaksi jual beli secaraonline.Hal ini dikarenakan transaksi melaluionlinedapat

mempermudah UKM dalammenjual produk-produk yang mereka miliki tanpa harus memiliki tokooffline.Untuk yang telah memiliki tokooffline, Bukalapak mengharapkan dengan adanyasitus tersebut dapat membantu meningkatkan penjualan tokoofflinetersebut Dalam perkembangannya, kemajuan teknologi telah mempengaruhi caramanusia melakukan proses transaksi(Ustadianto,Ariani:20 07).Komunikasi danpertukaran informasi pada kegiatan bisnis menjadi semakin mudah dengan adanyainternet sehingga perusahaan dapat 
melakukan aktivitas bisnisnya secaraelektronik khususnya aktivitas hubungan perusahaan dengan konsumen dan mitrakerja perusahaan atau disebute-commerce.E-

commerceadalah

penggunaaninternetdan web untuk transaksi bisnis dan dane-commercesecara digital mampumempermudah

transaksi komersial antar organisasi dan antara organisasi

denganindividu(Laudon, 2010:8 ).Menteri Komunikasi dan Informatika,

Rudiantaramenyatakan

bahwapotensi perdaganganecommercepada tahun 2015diperkirakan mencapai US\$ 20 miliar atau sekitar Rp 280 triliun. Nilainya lebihbesar dari pencapaian tahun 2014 sebesar US\$ 12 miliar dan senilai US\$ 8 milliar

3pada 2013. Saban tahun, pertumbuhannya sekitar 60 persen hingga 70 persen(Katadata.co.id, 2015).Menurut data hasil riset Asosiasi Penyelenggara Jasa Internet Indonesia(APJII) tahun 2014 mengungkapkan pengguna internet di Indonesia terhitungsejak tahun 2005 hingga tahun 2014 tumbuh sebesar 72,1 juta dengan penetrasi27,1 persen. Sedangkan jumlah pengguna internet di Indonesia tahun 2014mencapai 88,1 juta orang hingga akhir tahun, tumbuh 16,2 juta dari tahunsebelumnya 71,9 juta dan memiliki penetrasi 34,9 persen(APJII, 2014).

\section{B. PEMBAHASAN / STUDI KASUS}

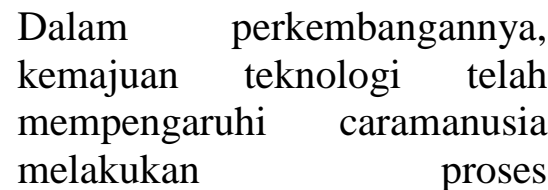
transaksi(Ustadianto,Ariani:20

07).Komunikasi danpertukaran informasi pada kegiatan bisnis menjadi semakin mudah dengan adanyainternet sehingga perusahaan dapat melakukan aktivitas bisnisnya secaraelektronik khususnya aktivitas hubungan perusahaan dengan konsumen dan mitrakerja perusahaan atau disebute-commerce.E-

commerceadalah

penggunaaninternetdan web untuk transaksi bisnis dan dane-commercesecara digital mampumempermudah

transaksi komersial antar organisasi dan antara organisasi

denganindividu(Laudon, 2010:8 ).Menteri Komunikasi dan Informatika,

Rudiantaramenyatakan

bahwapotensi perdaganganecommercepada tahun 2015diperkirakan mencapai US\$ 20 miliar atau sekitar Rp 280 triliun. Nilainya lebihbesar dari pencapaian tahun 2014 sebesar US\$ 12 miliar dan senilai US\$ 8 milliar 3pada 2013. Saban tahun, pertumbuhannya sekitar 60 
$\begin{array}{lll}\text { persen hingga } & 70\end{array}$

persen(Katadata.co.id,

2015).Menurut data hasil riset

Asosiasi Penyelenggara Jasa

Internet Indonesia(APJII) tahun

2014 mengungkapkan

pengguna internet di Indonesia terhitungsejak tahun 2005 hingga tahun 2014 tumbuh sebesar 72,1 juta dengan penetrasi27,1 persen. Sedangkan jumlah pengguna internet di Indonesia tahun 2014mencapai 88,1 juta orang hingga akhir tahun, tumbuh 16,2 juta dari tahunsebelumnya 71,9 juta dan memiliki penetrasi 34,9 persen(APJII, 2014).

Meskipunjumlah pengguna internet dan potensi pasarecommercediIndonesia terus meningkat, namun persentase aktivitas jual belionlineyangdilakukan

masyarakat Indonesia masih lebih sedikit jika dibandingkan denganpenggunaan jejaring sosial dan aktivitasbrowsing.Hal tersebut didasari data hasilriset APJII (Asosiasi Penyelenggara Jasa Internet Indonesia) yangmengungkapkanaktivitas yang dilakukan masyarakat Indonesia ketika mengaksesinternetyaitumenggu nakanjejaringsosial sebesar $87,4 \%$,browsingsebesar68,7\%, sedangkan aktivitas jual belionlinehanya sebesar $11 \%$ Berdasarkan survei McKinsey pada akhir 2013, 56 persen respondenmenilai belanjaonlineterkadang menipu. Sedangkan pembayaran belanjaonlinetidak aman dinilai oleh 35 persen responden(Katadata, 2015).Hal inididukungpendapatyang mengatakan bahwasebagian besar pelanggan masih ragu untukmelakukan pembelian melalui web milik penjual yang belum

dikenalnya(LaudondanLaudon: 2005).Transaksionlineyang dilakukan tanpa proses tatap muka tentu membukakesempatan yang lebih besar bagi oknum tak bertanggung jawab untuk melakukantindak penipuan. Hal inilah yang melatarbelakangi lahirnya berbagaistartupinovatif yang berupaya untuk melindungi pihak penjual dan pihak pembeli

dalamsebuahtransaksionline(M axmanroe, 2015). Secara umum, terdapat tiga jenisecommerceyang dapat dibedakan berdasarkan model bisnisnya yaituforumonlinedan iklan baris seperti Kaskus dan OLX. SitusBusiness toConsumer

(B2C)sepertiLazada dan Traveloka, sertaMarketplace Consumer toConsumer (C2C)sepertiBukalapak dan Tokopedia(Techinasia, 2015).Dari berbagai situsecommerceyang kini ada, Bukalapak merupakansalah satu situse-commerceyang menarik untuk diteliti karena beberapa alasan,Pertama,berdasarkan 
survey tokoonlinepopular di Indonesia oleh Tech In Asiaper 16 Maret 2016, Bukalapak menempati peringkat pertama untuk kategorimarketplace, diikuti oleh Tokopedia di peringkat kedua, serta Elevenia diperingkat ketiga. Model bisnise-

commercemarketplacesecara unik akan menjadipenengah bagi semua transaksi antara penjual dan pembeli. Seluruh pemaine-commercetersebut akan menyediakan layanan rekening bersama (rekberatauescrow) untuk memberikan perlindungan lebih kepada para penjual dan pembeli

berdasarkan hasil survey lembaga riset Telematika Sharing VisionDesember 2016 menunjukkan, lamanecommercelocal seperti Tokopedia danBukalapak sudah melewati trafik sekaligus peringkat localecommerceasingseperti

Amazon, Alibaba, eBay, OLX, juga Lazada. Dari sisi trafik , data SharingVision menunjukkanpageviewharian Bukalapak mencapai 7.764 juta danTokopedia 7.58 juta, sedangkan

jumlahmerchantBukalapak akhir tahun 2016sudah 510.000 unit dan Tokopedia 500.00 unit(Pikiran Rakyat, 10 Januari 2017).Hasil survey tersebut menunjukkan bahwa Bukalapak masihberada diataspesaingnya,Tokopedia.U ntuk saat ini belum ada data resmi dari pihak Bukalapak mengenaijumlah pasti transaksi yang telah dilakukan beberapa tahun terakhir.Oleh karenaitu peneliti mengumpulkan beberapa informasi berupastatementmengenainilait ransaksipada Bukalapak dari 2013 sampai dengan 2016 sebagai berikut.Bukalapak, salah satumarketplacecustomer to customer(C2C) terbesar dinegara ini, baru saja mengungkapkan beberapa data dan kemajuan yangdicapainya di tahun2013.Diluncurkan "secara tidak resmi" pada bulan Februari2010, Bukalapak sekarang memfasilitasi transaksi senilai Rp 500 juta setiapharinya atau lebih dari Rp15 miliarsetiap bulannya (Tech in Asia, 2014).Sejakdidirikan pada 2010 lalu, bisnismarketplaceini terus bertumbuh. Setiap tahunnyaselalu ada pertumbuhan transaksi hingga 5 kali lipat dari tahun sebelumnya.

\section{ID SECURITY QWTD4452377-ASP-5244107}

\section{KESIMPULAN}

Berdasarkanhasilobservasidari beberapastatementCEO

Bukalapak,yangtelahdiuraikan diatas,makaselaludidapatipenin gkatan transaksi dari tahunke tahundari tahun 2013 hingga 2015.Sedangkan, untukproses 
transaksi pada

Bukalapakterdapatmetodepemb ayarandenganrekeningescrowB ukalapak sebagai pihak ketiga, sehinggapembeli melakukan pembayaran langsung ke rekening penjual.Pada

setiap05101520253020132014

2015Transaksi

BukalapakTransaksiBukalapak TahunMiliar (Rp)

8transaksi,Bukalapakmenamba hkankode unikpada3digit terakhir dari totalbiaya yang harus dibayarhal tersebut berfungsi untuk memudahkan verifikasipembayaran secara otomatis (blog.bukalapak, 2016).Tiga digit kode unik tersebuttidak akan dikembalikan dan menjadi keuntungan bagi Bukalapak (Solusik,2016).Hasil

darisurvey pra penelitian terhadap 30 orang responden didapatkanbahwa100\%

konsumen menggunakan metode pembayaran yang telah disediakanoleh Bukalapak.Hal tersebut menunjukkan bahwa keputusan pembelian padaBukalapak baik, karena konsumen telah menggunakanmetode

pembayaran yangdisediakan sehingga Bukalapak mendapatkan keuntungan dari 3 digit kode uniktersebut.

\section{E. DISKUSI}

Saya bersama teman saya bernama TRIHAMSAH mendiskusikan materi ini dengan sangat baik Hasil diskusi dari materi ini adalah,

Bukalapak, salah satumarketplacecustomer to customer(C2C) terbesar dinegara ini, baru saja mengungkapkan beberapa data dan kemajuan yangdicapainya di tahun2013.Diluncurkan "secara tidak resmi" pada bulan Februari2010, Bukalapak sekarang memfasilitasi transaksi senilai Rp 500 juta setiapharinya atau lebih dari Rp15 miliarsetiap bulannya (Tech in Asia, 2014).Sejakdidirikan pada 2010 lalu, bisnismarketplaceini terus bertumbuh. Setiap tahunnyaselalu ada pertumbuhan transaksi hingga 5 kali lipat dari tahun sebelumnya.

Transaksionlineyang dilakukan tanpa proses tatap muka tentu membukakesempatan yang lebih besar bagi oknum tak bertanggung jawab untuk melakukantindak penipuan. Hal inilah yang melatarbelakangi lahirnya berbagaistartupinovatif yang berupaya untuk melindungi pihak penjual dan pihak pembeli dalam sebuah transaksi online

Seiring dengan berjalannya waktu, Bukalapak semakin berkembangdengan inovasi terbarunya untuk mempermudah para pengguna Bukalapak untuktransaksinya.Bukalapak memiliki program untuk 
memfasilitasi

parapelakuUKMyang ada di Indonesia untuk melakukan transaksi jual beli secaraonline.Hal ini dikarenakan transaksi melaluionlinedapat mempermudah UKM dalammenjual produk-produk yang mereka miliki tanpa harus memiliki tokooffline.Untuk yang telah memiliki tokooffline, Bukalapak mengharapkan dengan adanyasitus tersebut dapat membantu meningkatkan penjualan toko offline tersebut.

\section{F. REFERENCE}

[1] O. M. Febriani and A. S. Putra, "Sistem Informasi Monitoring Inventori Barang Pada Balai Riset Standardisasi Industri Bandar Lampung," J. Inform., vol. 13, no. 1, pp. 90-98, 2014.

[2] A. S. Putra, "Paperplain: Execution Fundamental Create Application With Borland Delphi 7.0 University Of Mitra Indonesia," 2018.

[3] A. S. Putra, "2018 Artikel Struktur Data, Audit Dan Jaringan Komputer," 2018.

[4] A. S. Putra, "ALIAS MANAGER USED IN DATABASE DESKTOP STUDI CASE DB DEMOS."

A. S. Putra, "COMPREHENSIVE SET OF PROFESSIONAL FOR DISTRIBUTE COMPUTING."

[6] A. S. Putra, "DATA
ORIENTED RECOGNITION IN BORLAND DELPHI 7.0."

[7] A. S. Putra, "EMBARCADERO DELPHI XE 2 IN GPUPOWERED FIREMONKEY APPLICATION."

[8] A. S. Putra, "HAK ATAS KEKAYAAN INTELEKTUAL DALAM DUNIA TEKNOLOGY BERBASIS REVOLUSI INDUSTRI 4.0."

[9] A. S. Putra, "IMPLEMENTASI PERATURAN

PERUNDANGAN UU. NO 31 TAHUN 2000 TENTANG DESAIN INDUSTRI BERBASIS INFORMATION TECHNOLOGY."

[10] A. S. Putra, "IMPLEMENTATION OF PARADOX DBASE."

[11] A. S. Putra, "IMPLEMENTATION OF TRADE SECRET CASE STUDY SAMSUNG MOBILE PHONE."

[12] A. S. Putra, "IMPLEMENTATION

PATENT FOR APPLICATION WEB BASED CASE STUDI WWW. PUBLIKLAMPUNG. COM."

[13] A. S. Putra, "IMPLEMENTATION SYSTEM FIRST TO INVENT IN DIGITALLY INDUSTRY."

[14] A. S. Putra, "MANUAL REPORT \& INTEGRATED DEVELOPMENT

ENVIRONMENT BORLAND DELPHI 7.0."

[15] A. S. Putra, "PATENT AS RELEVAN SUPPORT RESEARCH."

[16] A. S. Putra, "PATENT FOR 
RESEARCH STUDY CASE OF APPLE. Inc."

[17] A. S. Putra, "PATENT PROTECTION FOR APPLICATION INVENT."

[18] A. S. Putra, "QUICK REPORT IN PROPERTY PROGRAMMING."

[19] A. S. Putra, "REVIEW CIRCUIT LAYOUT COMPONENT

REQUIREMENT ON ASUS NOTEBOOK."

[20] A. S. Putra, "REVIEW TRADEMARK PATENT FOR INDUSTRIAL TECHNOLOGY BASED 4.0."

[21] A. S. Putra, "TOOLBAR COMPONENT PALLETTE IN OBJECT ORIENTED PROGRAMMING."

[22] A. S. Putra, "WORKING DIRECTORY SET FOR PARADOX 7."

[23] A. S. Putra, "ZQUERY CONNECTION IMPLEMENTED PROGRAMMING STUDI CASE PT. BANK BCA Tbk."

[24] A. S. Putra, D. R. Aryanti, and I. Hartati, "Metode SAW (Simple Additive Weighting) sebagai Sistem Pendukung Keputusan Guru Berprestasi (Studi Kasus: SMK Global Surya)," in Prosiding Seminar Nasional Darmajaya, 2018, vol. 1, no. 1, pp. 85-97.

[25] A. S. Putra and O. M. Febriani, "Knowledge Management Online Application in PDAM Lampung Province," in Prosiding International conference on Information Technology and Business
(ICITB), 2018, pp. 181-187.

[26] A. S. Putra, O. M. Febriani, and B. Bachry, "Implementasi Genetic Fuzzy System Untuk Mengidentifikasi Hasil Curian Kendaraan Bermotor Di Polda Lampung," SIMADA (Jurnal Sist. Inf. dan Manaj. Basis Data), vol. 1, no. 1, pp. 21-30, 2018.

[27] A. S. Putra, H. Sukri, and K. Zuhri, "Sistem Monitoring Realtime Jaringan Irigasi Desa (JIDES) Dengan Konsep Jaringan Sensor Nirkabel," IJEIS (Indonesian J. Electron. Instrum. Syst., vol. 8, no. 2, pp. 221-232.

[28] D. P. Sari, O. M. Febriani, and A. S. Putra, "Perancangan Sistem Informasi SDM Berprestasi pada SD Global Surya," in Prosiding Seminar Nasional Darmajaya, 2018, vol. 1, no. 1, pp. 289-294. 